\title{
PENGARUH KUALITAS PELAYANAN TERHADAP KEPUASAN PELANGGAN DISC TARRA DI KOTA BOGOR 2012
}

\author{
Sri Hidajati Ramdani \\ Dosen Tetap Fakultas Ekonomi \\ Universitas Pakuan \\ Nendi Alamsyah \\ Mahasiswa Fakultas Ekonomi \\ Universitas Pakuan
}

\begin{abstract}
ABSTRAK
Disc Tarra layanan di kota Bogor menunjukkan pertumbuhan data pelanggan tidak stabil, karena peningkatan dan penurunan jumlah pelanggan sehingga perusahaan belum mampu untuk meningkatkan kualitas layanan untuk kepuasan pelanggan tidak tercapai.

Tujuan penelitian adalah untuk mengetahui pengaruh kualitas pelayanan pada kepuasan pelanggan Disc Tarra di Bogor. Penelitian jenis verifikasi, teknik penelitian dalam bentuk statistik inferensial, metode penelitian pengumpulan data dengan analisis Diagram Kartesius, uji statistik Chi Square,

Dihitung berdasarkan uji hipotesis terdapat kualitas yang signifikan dari layanan untuk kepuasan pelanggan, sehingga dapat disimpulkan bahwa kualitas pelayanan dapat meningkatkan kepuasan pelanggan di Disc Tarra di kota Bogor.
\end{abstract}

Kata kunci: Tangible, Empathy, Reability, Responsiveness, Assurance.

\section{Latar Belakang}

Pada dasarnya tujuan didirikannya perusahaan adalah untuk memperoleh laba, mempertahankan kelangsungan hidup perusahaan dan memperluas atau mengembangkan perusahaan. Maka setiap perusahaan harus memahami tentang perilaku konsumen serta perilaku pembelian mereka agar tujuan perusahaan tersebut tercapai, sehingga perusahaan perlu melakukan upaya-upaya mendengarkan suara pelanggannya, agar terdapat pemahaman terhadap suara pelanggan sebagai prasyarat peningkatan mutu dan produktifitas terus menerus dalam mencapai total kepuasan pelanggan. Suara pelanggan menjadi hal yang sangat penting dalam menentukan mutu 
pelayanan, karena yang menentukan baik atau buruknya perusahaan adalah konsumen bukan produsen.

Namun demikian, pada umumnya perusahaan-perusahaan mengalami kesulitan dalam memonitor, memahami dan menganalisis perilaku konsumen secara tepat dan benar, mengingat banyaknya faktor yang mempengaruhi perbedaan perilaku konsumen. Disc Tarra yang bergerak dalam industri jasa khususnya di bidang musik dan perfilman, harus mampu untuk memenangkan persaingan yang kompetitif terlebih pada masa sekarang, dimana adanya upaya untuk memberikan pelayanan terhadap pelanggan sehingga perusahaan dapat mengidentifikasikan kebutuhan dan keinginan konsumen, memperkecil atau menghilangkan tingkat kelalaian karyawan, dan yang terpenting adalah bahwa perusahaan dengan jelas menentukan dan mengkomunikasikan tingkat pelayanan yang diberikan, sehingga para konsumen mengetahui kepuasan apa yang akan mereka dapatkan.

Adapun tujuan penelitian yang ingin dicapai meliputi hal-hal dapat memberikan

1. Untuk mengetahui besaran tingkat kepuasan pelanggan Disc Tarra di kota Bogor

2. Untuk mengetahui pengaruh kualitas pelayanan terhadap kepuasan pelanggan pada Disc Tarra di kota Bogor

\section{Metode Penelitian}

Metode penelitian yang penulis gunakan adalah explanatory survey. Dimana didalamnya akan diketahui sejauh mana fenomena yang ada dalam bentuk hubungan antar variabelnya. Alat analisis yang digunakan berupa Diagram Kartesius dan analisis Chi-Square, prosedur pengumpulan data menggunakan sumber primer terdiri dari kuesioner dan wawancara.

\section{Hasil Dan Pembahasan}

1. Penerapan Kualitas Pelayanan Disc Tarra di kota Bogor ( mall Botani Square dan Ekalokasari Plaza )

Untuk membahas bagaimana penerapan Disc Tarra di Kota Bogor, maka penulis memberikan data sebagai berikut : 
a. Untuk setiap pembelian di atas Rp. 250.000, akan mendapatkan 25-50\% jika konsumen tersebut mempunyai kartu kredit Mandiri (syarat dan ketentuan berlaku).

b. Adanya penukaran poin untuk pembelian berapa saja jika konsumen mempunyai kartu kredit City bank (syarat dan ketentuan berlaku).

c. Setiap pembelian di atas Rp. 250.000, akan mendapatkan free Mocktail (Power Puff Moctail, Pink Panther, Madagaskar, dan Wolverine)

2. Tingkat Kepuasan Pelanggan Terhadap Kualitas Pelayanan Disc Tarra di kota Bogor.

Untuk membahas bagaimana tingkat pelanggan terhadap kepuasan pelanggan maka penulis menggunakan tingkat kesesuaian dan diagram kartesius, adapun tingkat kesesuaian, bertujuan untuk mengetahui tingkat kesesuaian antara skor tingkat kinerja atau pelaksana dengan skor tingkat kepentingan atau harapan pelanggan. Rumus yang digunakan adalah sebagai berikut: Tki $=\frac{X i}{Y i} \times 100 \%$

$$
\begin{aligned}
\mathrm{Tki} & =\frac{13201}{11891} \times 100 \% \\
& =111,02 \%
\end{aligned}
$$

Kartesius :

Diagram kartesius dibagi menjadi empat kuadran, yang akan dijelaskan berikut ini :

a) Kuadran A (Prioritas Utama)

Indikator yang berada pada kuadran A artinya indikator ini memiliki tingkat kinerja di bawah rata-rata, tetapi tingkat harapannya cukup tinggi. Tetapi pada kenyataannya Disc Tarra di Kota Bogor, dinilai tidak terdapat Indikator Kuadran A.

b) Kuadran B (Pertahankan Prestasi)

Pada kuadran ini, indikator yang menjadi kekuatan perusahaan karena memiliki kinerja dan harapan yang tinggi adalah indikator yang berada pada kuadran B.

c) Kuadran C (Prioritas Rendah) 
Indikator yang berada pada kuadran $\mathrm{C}$ adalah indikator yang memiliki kinerja dan harapan relatif rendah. Tetapi pada kenyataannya Disc Tarra di Kota Bogor, dinilai tidak terdapat Indikator Kuadran C.

d) Kuadran D (Berlebihan)

Menunjukkan faktor yang kurang penting, akan tetapi pelaksanaannya berlebih dianggap kurang penting tetapi sangat memuaskan. Indikator tersebut adalah :

Kebersihan dan kenyamanan outlet Disc Tarra secara umum ( No. 2)

1) Fisik CD audio, DVD, Blu-Ray, dan accesoris yang ada di Disc Tarra (No.3)

2) Crew Disc Tarra dalam cara menunjukkan rasa percaya diri dan bersikap siap melayani/membantu pelanggan. (No.12)

3) Kualitas crew Disc Tarra memberikan pelayanan kepada pelanggan hingga tuntas (No.13)

4) Keramahan dan kesopanan crew maupun kepala toko / staff (No.14)

\section{Pengaruh Kualitas Pelayanan Terhadap Tingkat Kepuasan Pelanggan Disc}

\section{Tarra di kota Bogor.}

Untuk mengetahui pengaruh antara kualitas pelayanan terhadap kepuasan pelanggan, penulis menggunakan alat analisis Chi-Square untuk tingkat kinerja. Dengan menggunakan $\alpha=0,05$ maka diperoleh nilai CS tabel sebesar 79,08.

\section{a. Uji Hipotesis Chi-Square}

1) Tingkat Kinerja tehadap Kualitas Pelayanan Disc Tarra di Kota Bogor

Untuk menguji hubungan antara kualitas pelayanan dengan kepuasan pelanggan, penulis akan membandingkan antara CS hitung dengan Cs tabel. Jika CS hitung > CS tabel maka Ho ditolak artinya kualitas pelayanan jika dilihat pada tingkat harapan sangat berpengaruh kepuasan pelanggan Disc Tarra di kota Bogor dengan menggunakan $\alpha=0,05$ dan tingkat kepercayaan $95 \%$

Apabila diukur kuatnya hubungan antara variabel independent (kualitas pelayanan) dengan variabel dependent (kepuasan pelanggan) pada tingkat kinerja, maka dapat dihitung dengan menggunakan rumus kontingensi atau $\mathrm{C}$ sebagai berikut : 


$$
C=\sqrt{\frac{108.67}{108.67+100}}=\sqrt{\frac{108.67}{208.67}}=0,521
$$

\section{2) Tingkat Harapan terhadap Kualitas Pelayanan}

Untuk menguji hubungan antara kualitas pelayanan dengan kepuasan pelanggan, penulis akan membandingkan antara CS hitung dengan Cs tabel. Jika CS hitung > CS tabel maka Ho diterma artinya pelayanan pada tingkat harapan sangat berperan dalam upaya meningkatkan kepuasan pelanggan Disc Tarra di Kota Bogor dengan menggunakan $\alpha=0,05$ dan tingkat kepercayaan $95 \%$.

Apabila diukur kuatnya hubungan antara variabel independent (kualitas pelayanan) dengan variabel dependent (kepuasan pelanggan) pada tingkat harapan, maka dapat dihitung dengan menggunakan rumus kontingensi atau $\mathrm{C}$ sebagai berikut :

$$
C=\sqrt{\frac{95.25}{95.25+100}}=\sqrt{\frac{95.25}{195.25}}=0,488
$$

\section{Kesimpulan}

1. Berdasarkan hasil penelitian dari penilaian pelayanan Disc Tarra terkait kepuasan pelanggan Disc Tarra di Kota Bogor, pada segi indikator bukti langsung tingkat kinerja perusahaan sudah memenuhi harapan pelanggan atau cukup puas, dari segi pelayanan dengan empati kinerja perusahaan sudah memenuhi kebutuhan pelanggan yaitu puas dan cukup puas. Tingkat kinerja perusahaan pada kehandalan dan ketanggapan sudah cukup puas, adapun dari jaminan yang dirasakan pelanggan puas dan cukup puas.

2. Dalam analisis kualitas pelayanan Disc Tarra di Kota Bogor berjalan dengan baik, perusahaan itu sendiri mempunyai beberapa kriteria yaitu :
a. Bukti Langsung (Tangible)
b. Perhatian (Empathy)
c. Kehandalan (realibility.
d. Daya Tanggap (Responsiveness)
e. Jaminan (Assurance)

\section{Daftar Pustaka}


Achmad Zein. 2009. Aplikasi Pemasaran dan Salesman Ship. Edisi ketiga. Mitra Wacana Media. Jakarta

Ali Hasan. 2008. Marketing, Medpress, Yogyakarta.

Arman Hakim Nasution, Indung Sudarso, dan Lantip Tri Sunarno. 2006. Manajemen Pemasaran. Erlangga, Jakarta

Buchari Alma, 2009. Manajemen Pemasaran dan Pemasaran Jasa, cetakan ke-5. Alfabeta. Bandung.

Eva Z. Yusuf dan Lesley Williams. 2007. Manajemen Pemasaran:Studi kasus Indonesia. Alih bahasa: Abdul Rosyid, PPM. Jakarta..

Fandy Tjiptono. 2009. Service Marketing, Edisi Pertama. Marknesis. Yogyakarta.

Husein Umar. 2005. Riset Pemasaran dan Perilaku Konsumen. PT Gramedia Pustaka Utama, Jakarta.

Kotler , P and K. L. Keller. 2009. Marketing management, 13th. Ed. Upper sddle River, NJ.: Prentice Hall International, Inc.

Rambat Lupiyodi dan A. Hamdani. 2006. Manajemen Pemasaran Jasa. Salemba Empat, Jakarta.

Schiffman.G, Leon, Leslie, Lazar, Kanuk. 2007. Prilaku Konsumen : Gramedia Alih Bahasa Zoelkifli Kasip

Sofjan Assauri. 2007. Manajemen Pemasaran. Erlangga, Jakarta. 